\title{
Effect of Experimental Gestational Diabetes Mellitus on Mechanical Sensitivity, Capsaicin-Induced Pain Behaviors and Hind Paw Glabrous Skin Innervation of Male and Female Mouse Offspring
}

\author{
Enriqueta Munoz-Islas (DD \\ Cecilia Esther Elizondo- \\ Martinez' \\ Mariela Gutierrez-Lopez' \\ Rosa Issel Acosta-Gonzalez' \\ Veronica Zaga-Clavellina ${ }^{2}$ \\ Addy Cecilia Helguera-Repetto ${ }^{3}$ \\ Martha Beatriz Ramirez- \\ Rosas (iD) \\ E Alfonso Romero-Sandoval (iD) ${ }^{4}$ \\ Juan Miguel Jimenez- \\ Andrade (D) ${ }^{1}$ \\ 'Unidad Académica Multidisciplinaria \\ Reynosa-Aztlán, Universidad Autónoma \\ de Tamaulipas, Reynosa, Tamaulipas, \\ Mexico; ${ }^{2}$ Departamento de Fisiología \\ y Desarrollo Celular, Instituto Nacional \\ de Perinatología, Ciudad de México, \\ Mexico; ${ }^{3}$ Departamento de \\ Inmunobioquímica, Instituto Nacional de \\ Perinatología, Ciudad de México, Mexico; \\ ${ }^{4}$ Department of Anesthesiology, Wake \\ Forest University School of Medicine, \\ Winston Salem, NC, USA
}

\begin{abstract}
Purpose: Gestational diabetes mellitus (GDM) induces cardiovascular and metabolic disturbances in offspring. However, the effects of GDM in pain processing in offspring and whether male and female offspring are equally affected is not well known. Thus, we determined: i) whether GDM in mice affects offspring hindpaw mechanical sensitivity, capsaicin-induced spontaneous pain-like behaviors, and epidermal nerve fiber density (ENFD); and ii) whether there is sexual dimorphism in these parameters in offspring from GDM dams.
\end{abstract}

Methods: GDM was induced in pregnant ICR mice via i.p. streptozotocin (STZ). Then, glucose levels from dams and offspring were determined. Male and female offspring 2-3 months of age were evaluated for: a) baseline mechanical sensitivity of the hind paw by using von Frey filaments; b) number of flinches and time spent guarding induced by intraplantar capsaicin (0.1\%); and c) density of PGP-9.5 and CGRP axons in the epidermis from the hind paw glabrous skin.

Results: Prepartum levels of glucose in STZ-treated dams were significantly increased compared to vehicle-treated dams; however, GDM or vehicle offspring displayed normal and similar blood glucose levels. Male and female GDM offspring showed significantly greater mechanical sensitivity and capsaicin-induced pain behaviors compared to vehicle offspring. Male GDM offspring displayed a slightly more intense nociceptive phenotype in the capsaicin test. PGP-9.5 and CGRP ENFD in hind paw glabrous skin were greater in male and female GDM offspring versus their controls. Sexual dimorphism was generally not observed in GDM offspring in most of the studied parameters.

Conclusion: These results suggest GDM induced greater pain-like behaviors in adult offspring regardless of sex along with an increased ENFD of PGP-9.5 and CGRP in the hind paw glabrous skin. We show that GDM peripheral neuropathy differs from diabetic peripheral neuropathy acquired in adulthood and set the foundation to further study this in human babies exposed to GDM.

Keywords: offspring, long-term effects, nociception, CGRP

\section{Introduction}

GDM is the most common medical complication of pregnancy and it has become one of the leading causes of maternal and child mortality and morbidity worldwide. ${ }^{1-4}$ During pregnancy, women with GDM may be afflicted with several comorbidities or complications including preeclampsia, polyhydramnios, premature
Correspondence: Enriqueta Munoz-Islas Calle 16 y Lago de Chapala, Col. Aztlán C.P.88740, Reynosa, Tamaulipas, Mexico Tel +525532076849

$\mathrm{Fax}+528999230622$

Email e.munoz.islas@gmail.com 
rupture of membrane or caesarean section. ${ }^{2-4}$ Additionally, the offspring born from women with GDM are prone to suffer from macrosomia, congenital deformities, hypoglycemia, respiratory distress syndrome and neonatal trauma. ${ }^{4,5}$ Recent studies have shown a strong association between GDM and the development of some long-term health conditions for both the mother and offspring, including obesity, ${ }^{6}$ type- 2 diabetes ${ }^{7}$ and cardiovascular diseases. ${ }^{8,9}$

Preclinical studies have reported that GDM may also affect nociceptive processing in the offspring. Neurons of the medullary dorsal horn (a critical anatomical site for the processing of orofacial nociceptive information) from offspring of mice with diabetes have a higher sensitivity to GABA, which is a major inhibitory neurotransmitter in the CNS and has a major role in pain regulation and nociceptive transmission. ${ }^{10}$ Additionally, it has recently been shown that offspring from rats with alloxan-induced GDM have a significantly greater a) baseline sensitivity to thermal stimulation, b) mechanical sensitivity after carrageenan injection and $\mathrm{c}$ ) percentage of substance $\mathrm{P}$ and IB4 neuron profiles in the lumbar DRG as compared to those values in offspring from rats treated with vehicle. ${ }^{11}$ Although these previous studies suggest that GDM may induce changes in the nociceptive system in offspring suggestive of diabetic peripheral neuropathy, there are still fundamental gaps in our current knowledge related to the effects of GDM in offspring in the context of diabetes and its potential neuropathic consequences. For example, 1) Diabetic peripheral neuropathy is correlated to hyperglycemic levels and is histopathologically characterized by a reduction in epidermal nerve fiber density (ENFD); however, it is unknown whether GDM affects the density of nerve fibers innervating the skin of offspring. And, 2) Diabetes affects men and women similarly, but males are at higher risk of developing diabetic peripheral neuropathy than females; ${ }^{12}$ however whether sexual dimorphism of diabetic peripheral neuropathy exists in GDM offspring has not yet been interrogated. Thus, the present study aims to bridge these gaps. Specifically, our aims are 1) to determine the state of mechanical sensitivity, spontaneous pain-behaviors evoked by intraplantar capsaicin, and the density of PGP9.5 and CGRP epidermal nerve fibers of hind paw glabrous skin in offspring from mice with GDM; and 2) determine whether a sex difference exists by comparing these parameters in female and male GDM offspring.

\section{Materials and Methods \\ General}

Animals

Adult ICR mice used for mating (17 female and 8 male) were obtained from Harlan Laboratories (Mexico City, Mexico), with an initial age of 7-9 weeks (body weight 20-25 g). Mice were housed at a temperature of $22 \pm 2{ }^{\circ} \mathrm{C}$, with a 12-hour light/dark cycle, and with free access to food and water. All the experiments were performed in accordance with the NIH Guide for Investigation of Experimental Pain in Animals ${ }^{13}$ and were approved by our local Ethics Committee of Unidad Académica Multidisciplinaria Reynosa-Aztlán, UAT (CEI-UAMRA -2019-12). Efforts were made to minimize the number of animals used.

\section{Reagents}

The compounds used in the present study were streptozotocin (STZ; catalog number S0130; Sigma-Aldrich Co.), capsaicin (catalog number M2028; Sigma-Aldrich Co.). Streptozotocin was dissolved in sodium citrate buffer $\mathrm{pH}$ $4.50 .1 \mathrm{M}$. Capsaicin $1 \%$ was dissolved in $20 \%$ of ethanol, $7 \%$ to polyethylene glycol sorbitan monooleate (Tween 80; catalog number P1754; Sigma-Aldrich Co.) and the dilution of $0.1 \%$ capsaicin was made with saline solution. Fresh solutions were prepared for each experiment. The doses of all compounds refer to their free bases.

\section{Gestational Diabetes Model}

Mice were mated overnight, two or three females per male. The presence of vaginal plug on the next morning indicated the gestation day 0.5 (GD0.5). Gestational diabetes was induced by intraperitoneal administration of STZ dissolved in sodium citrate buffer $\mathrm{pH} 4.5 \quad 0.1 \mathrm{M}$. STZ was administrated for three consecutive days as follows: $100 \mathrm{mg} / \mathrm{kg}$ on gestational day $7,100 \mathrm{mg} / \mathrm{kg}$ on gestational day 8 , and $80 \mathrm{mg} / \mathrm{kg}$ on gestational day 9 . Control animals received vehicle using the same treatment paradigm. ${ }^{14}$ Other pregnant mice were administered with sodium citrate buffer $\mathrm{pH} 4.50 .1 \mathrm{M}$ on the same days of gestation (vehicle group, VEH). Dams were randomly allocated to receive STZ or vehicle. The concentration of serum glucose through caudal vein was measured $(\mathrm{mg} / \mathrm{dL}$; Accutrend Plus, Roche) following an 8-hour fasting period, at baseline ( 24 hours before first STZ administration), at 48 hours after STZ administration (post-treatment), and on the GD16 (prepartum; Figure 1A). In each offspring group, mice were born from at least 4 different dams. 
A

\section{Dams}

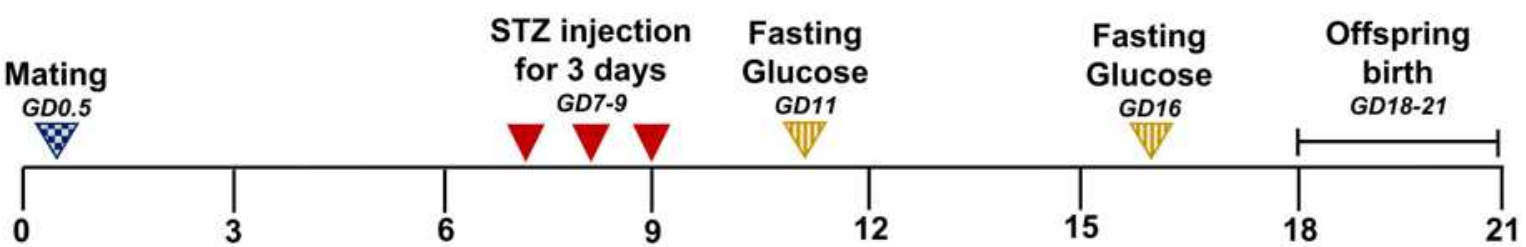

B

Days of gestation

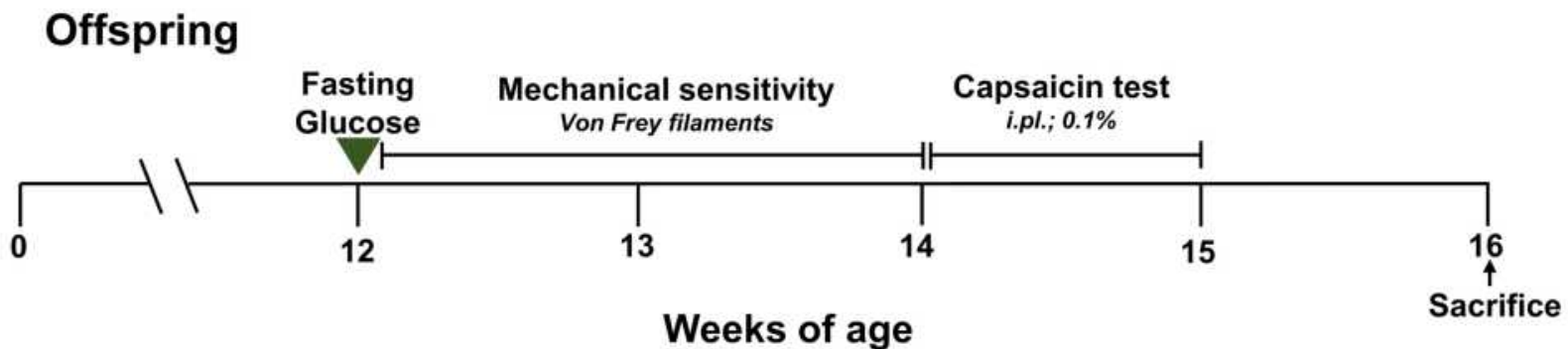

C

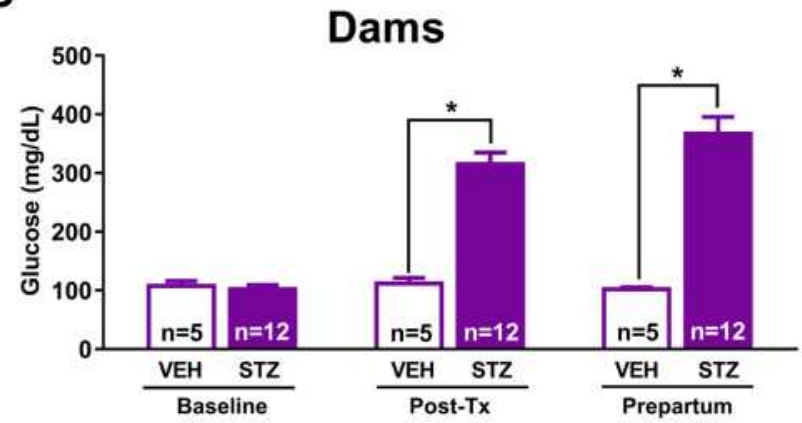

D

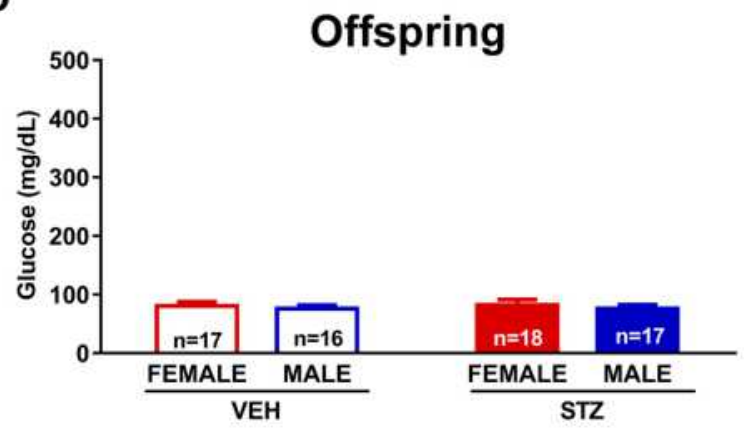

E

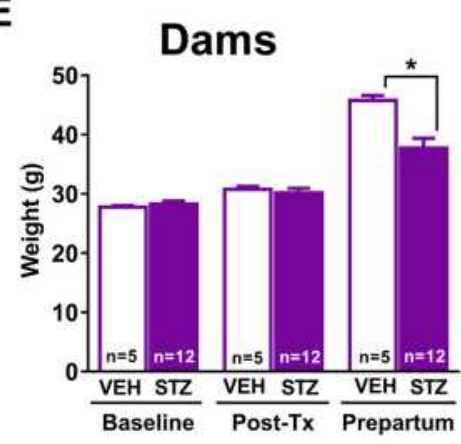

$\mathbf{F}$

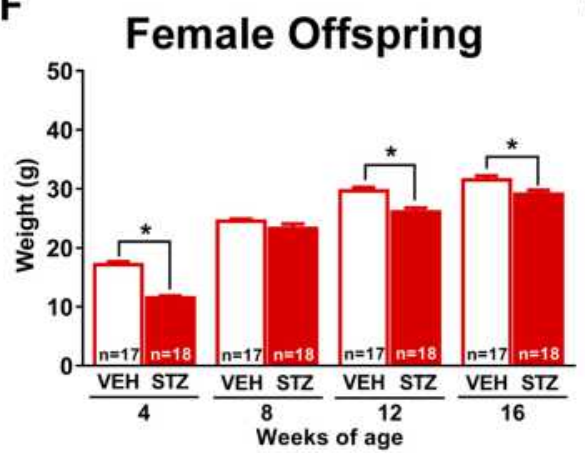

G

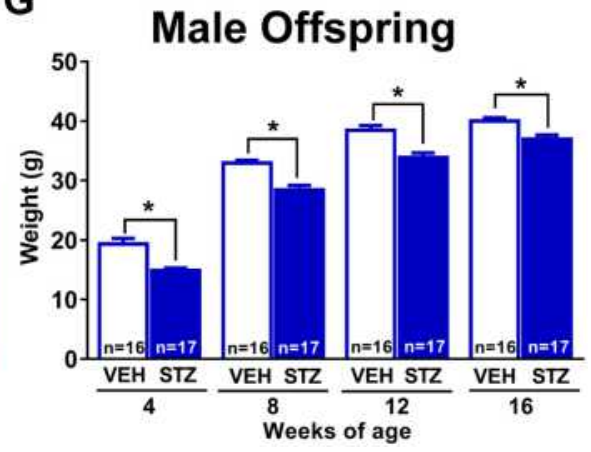

Figure I Experimental design, blood glucose levels and body weight in dams and offspring. Scheme showing the experimental design for the induction of diabetes during pregnancy (A) and all assays performed in offspring (B). Repeated administration of streptozotocin (STZ, $n=12)$ increased the blood glucose levels in pregnant mice compared to those in pregnant mice treated with vehicle $(\mathrm{VEH})$ at 48 hours after the last STZ administration and prepartum ( $\mathrm{n}=5)(\mathrm{C})$. There were no significant changes in glucose levels in both female and male offspring of dams treated with STZ versus those mice born from dams treated with VEH (D). The induction of diabetes during pregnancy significantly decreased the body weight of dams before partum versus VEH treated dams (E). Similarly, offspring born from dams treated with STZ showed a significantly decreased body weight in both female $(\mathbf{F})$ and male $(\mathbf{G})$ as compared to those offspring of dams treated with VEH. Data are presented as mean \pm SEM; ${ }^{*}$ < $<0.05$ vs VEH. Two-way repeated measures ANOVA followed by Tukey post-hoc test.

\section{Oral Glucose Tolerance Test in the Offspring} Oral glucose tolerance test (OGTT) was performed at 16 weeks of age in offspring from vehicle or STZ-treated dams. Mice fasted for $12 \mathrm{~h}$ and then received a bolus of aqueous glucose solution $(2 \mathrm{~g} / \mathrm{kg})$ that was delivered into the stomach by a gavage probe (20-gauge, $38 \mathrm{~mm}$ long 
curved, with a $21 / 4 \mathrm{~mm}$ ball end). Glucose quantification was performed in blood samples obtained from the tail vein using the calibrated glucometer system Accu-Chek Performa (Roche Diagnostic, Germany). Blood glucose quantification was performed at 0 (basal), 15, 30, 45, 60, and 120 min after the glucose load. ${ }^{15}$ Then, the area under the curve (AUC) for blood glucose was calculated.

\section{Evaluation of Mechanical Sensitivity in the Offspring}

Baseline mechanical sensitivity in the offspring was assessed weekly at 12,13 , and 14 weeks of age using the up-down method. ${ }^{16}$ Briefly, mice were placed on an elevated plastic cage with wire mesh floor for 60 minutes prior to testing. Tactile thresholds were measured with a series of calibrated von Frey filaments (Stoelting, Wood Dale, IL, USA) ranging from 2.44 to $4.56(0.02-4.00 \mathrm{~g})$. Each von Frey filament was pressed perpendicularly against the mid-plantar surface of the hind paw from below the mesh floor and held in place for 6- 8 seconds in a slightly bent form. Flinching of the paw was designated as a positive response. Mechanical values for the left and right hind paws were measured and the $50 \%$ probability of withdrawal threshold was calculated ${ }^{16,17}$ (Figure 1B). Once mechanical sensitivity was evaluated, mice were not tested for at least five days before next behavioral evaluation. All behavioral analyses were performed between 07:00 and 13:00 $\mathrm{h}$ by an observer blinded to the animals' experimental conditions.

\section{Evaluation of Pain-Like Behaviors Induced by Intraplantar Capsaicin in the Offspring} Capsaicin test was performed in offspring (female and males) at 15 weeks of age. Mice were placed in open acrylic observation chambers for $30 \mathrm{~min}$ to allow them to acclimatize to their surroundings. Mirrors were placed behind the chambers to enable unhindered observation. Animals were gently restrained while the intraplantar of the right hind paw was injected with $10 \mu \mathrm{L}$ of capsaicin ( $0.1 \%$; i.pl.) with a 30 -gauge needle. They were then returned to the chambers and nociceptive behavior was observed immediately after capsaicin injection. Spontaneous behavior was quantified as the number of flinches and time spent guarding of the injected paw for 5 minutes intervals over a period of 30 minutes in each experimental group. ${ }^{18,19}$ Flinches were defined as the number of times the animal raised its hind paw; the spontaneous guarding of the ipsilateral hind limb was defined as the amount of time the animals held the hind paw aloft while stationary. All behavioral analysis was performed between 07:00 and 13:00 $\mathrm{h}$ by an observer blinded to the animals' experimental conditions (Figure 1B).

\section{Tissue Harvesting and Immunohistochemistry}

Animals used for immunohistochemistry (IHC) were sacrificed at 16 weeks of age. It should be noted that mice used for IHC did not receive any capsaicin injection to exclude out potential effects of intraplantar injection on nerve fiber density. Mice were deeply anesthetized with a mixture of ketamine and xylazine $(100 / 10 \mathrm{mg} / \mathrm{kg})$ followed by transcardiac perfusion first with phosphate-buffered saline (PBS, $0.1 \mathrm{M}$, $\mathrm{pH} 7.4,4^{\circ} \mathrm{C}$ ) and followed by $4 \%$ paraformaldehyde in PBS. Glabrous skin from both hind paws were harvested, postfixed for 24 hours in the same fixative. Then, the hind paw skin was cryoprotected in $30 \%$ sucrose solution at $4^{\circ} \mathrm{C}$ until the tissue was processed for IHC. Serial frozen sections of the glabrous skin from the hind paws $(20 \mu \mathrm{m})$ were cut with a cryostat (Leica CM1900) and thaw-mounted on gelatincoated slides for processing. Posteriorly, the skin sections were washed in $0.1 \mathrm{M}$ PBS, three times for 10 minutes each, incubated for 1 hour with a blocking solution consisting of $3 \%$ Normal Donkey Serum and 0.3\% Triton X100 in 0.1 M PBS, and then incubated for 12 hours with a PGP-9.5 (Protein gene product 1:3000; Cedarlane; catalog number CL7756AP) or CGRP (Calcitonin gene-related peptide; 1:3000; Sigma Aldrich; catalog number C8198) primary antibody. Subsequently, preparations were washed in PBS and then incubated for 3 hours with the secondary antibody (Cy3 monoclonal donkey anti-rabbit 1:600; Jackson ImmunoResearch; Catalog number 711-165-152). Later, skin sections were washed in PBS, dehydrated through an alcohol gradient (70, 80, 90, and 100\%), cleared in xylene, and coverslipped with DPX mounting medium. For the quantification of the ENFD, initially, at least 10 separate skin sections were scanned at low magnification (10x) to identify the areas with the best integrity through an epifluorescence microscope (Axio Scope.A1, Carl Zeiss, Jena, Germany). Then, an image of this area of a least 5 different skin sections per mouse was obtained at 20x magnification using a Carl Zeiss scanning confocal laser microscope (model LSM 800, Jena, Germany). The Z-stack images were analyzed using ImageJ software (National Institutes of Health) to determine the total length of nerve fibers. To do this, the nerve fibers innervating the epidermis were manually traced using the freehand line tool. The determination of 
the area of evaluation was obtained by manually tracing the area of the epidermis. ENFD data are presented as the mean of the total length of nerve fibers $(\mu \mathrm{m})$ per $100 \mu \mathrm{m} 2$ of the epidermis. $^{20}$ This analysis was performed by an investigator that was blinded to group allocations.

\section{Statistical Analysis}

The results are expressed as mean \pm standard error of the mean (SEM) for each experimental group. Curves were constructed by plotting the glucose levels, the number of flinches and the guarding time as a function of time. Area under the curve (AUC) were constructed and compared among groups. Experiments were analyzed by using two or three-way repeated measures analysis of variance (ANOVA) or two-way ANOVA followed by Tukey posthoc test comparison where appropriate. Statistical significance was accepted at $p<0.05$. All statistical analyses were performed using GraphPad Prism version 8.0 ${ }^{\circledR}$ software package for Windows (GraphPad Software Inc., San Diego, CA, U.S.A.).

\section{Results}

\section{Effects of Experimental GDM on Blood Glucose Levels and Body Weight in Dams and Offspring}

Dams treated with STZ are considered to experience GDM when serum glucose concentrations are higher than $200 \mathrm{mg} / \mathrm{dL} .^{21,22}$ Based on this criterium, GDM induction success rate was $70.59 \%$ in our mouse model. Fasting blood glucose levels were significantly higher in STZ dams at GD11 $(315.25 \pm 19.48 \mathrm{mg} / \mathrm{dL})$ and prepartum (366.75 $\pm 29.03 \mathrm{mg} / \mathrm{dL})$ compared to those dams treated with VEH $(111.8 \pm 9.46$ and $101.8 \pm 3.22 \mathrm{mg} / \mathrm{dL}$, respectively) $\left[\mathrm{F}_{(1,15)}=44.3\right.$; Figure $\left.1 \mathrm{C}\right]$. Moreover, the induction of GDM significantly decreased the body weight of dams before partum versus VEH treated dams $\left[\mathrm{F}_{(1,15)}=8.388\right.$; Figure 1E].

There were no significant changes in glucose levels in both female or male offspring from STZ dams compared to offspring from VEH dams (Figure 1D) at 12 weeks of age. A significant decrease in body weight was observed in female $\left[\mathrm{F}_{(1,41)}=43.55\right.$; Figure $\left.1 \mathrm{~F}\right]$ and male $\left[\mathrm{F}_{(1,35)}=48.96\right.$; Figure $\left.1 \mathrm{G}\right]$ offspring from dams treated with STZ versus offspring from dams treated with VEH. Additionally, we calculated the percentage of body weight gain of dams and offspring. The weight gain was significantly smaller in dams treated with STZ as compared to dams treated with vehicle at 16 gestation days $\left[\mathrm{F}_{(1,15)}=39.38\right.$; Table 1]. On other hand, the weight gain was significantly greater in the female offspring from STZ-treated dams as compared to female offspring from VEH-treated dams at 8, 12 and 16 weeks-old $\left[\mathrm{F}_{(3,76)}=16.54\right.$; Table 1]. Likewise, the weight gain in male offspring from STZ-treated dams was significantly greater than that found in male offspring from VEHtreated dams at 16 weeks-old $\left[\mathrm{F}_{(3,76)}=16.54\right.$; Table 1]. These findings are in accordance with the hypercaloric milk that GDM dams might have, ${ }^{23}$ and the fact that offspring of GDM dams display hyperphagia and overweight during their life. ${ }^{24,25}$ Even though male offspring

Table I Percentage Weight Gain in Dams and in Female and Male Offspring

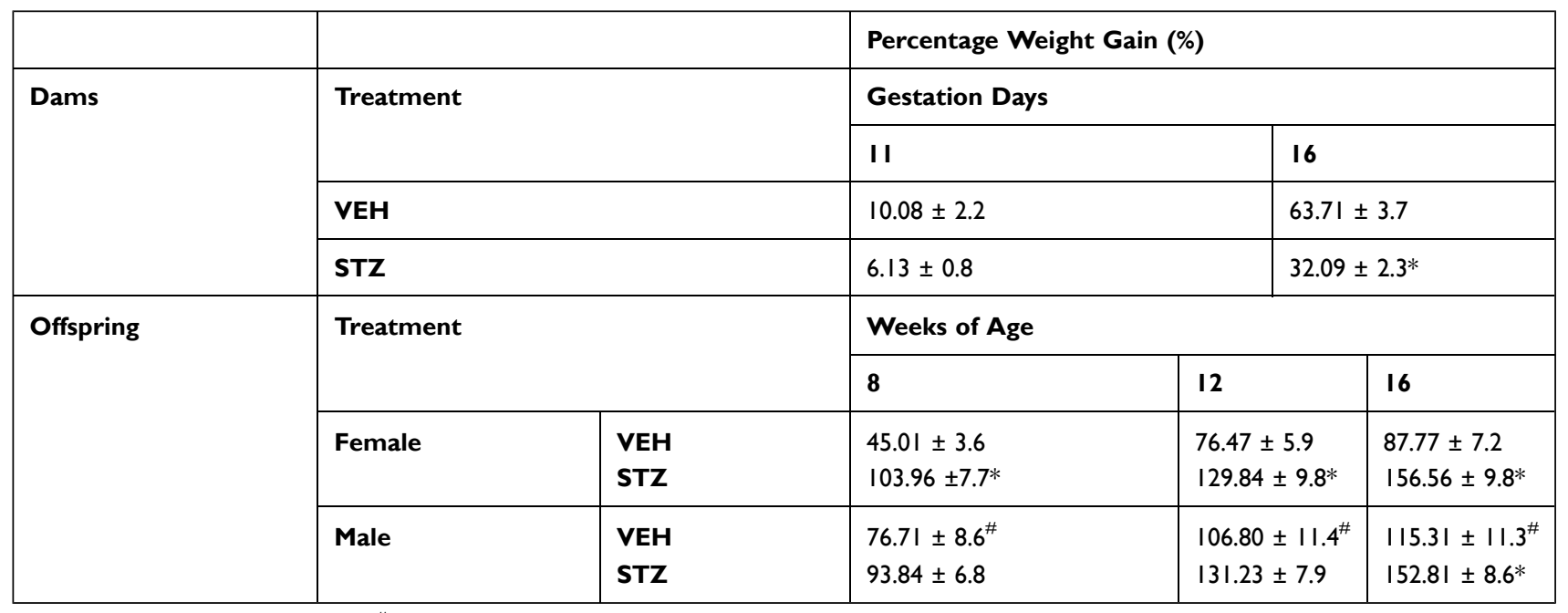

Notes: ${ }^{*} p<0.05$ vs respective control; ${ }^{*} p<0.05$ VEH female vs VEH male. Two-way repeated measures ANOVA with Tukey post-hoc test. Abbreviations: VEH, vehicle; STZ, streptozotocin. 
from VEH treated dams gained more weight than female counterparts $\left[\mathrm{F}_{(9,228)}=8.896\right.$; Table 1], we did not find any difference in body weight gain in offspring of STZtreated dams at any time point studied (Table 1).

\section{Effects of Experimental GDM on Oral Glucose Tolerance in Offspring}

In order to rule out the possibility that STZ given to pregnant mice has a potential toxic effect on fetus pancreas, we conducted the OGTT in offspring of STZ and vehicle treated dams (Figure 2A and B). We observed that GDM offspring displayed a similar blood glucose level curve to vehicle offspring following OGTT (Figure 2A), and the area under de curve was not different among the groups (Figure 2B). When we investigated sexual dimorphism in the OGTT we found no differences in male and female offspring of any of the studied groups, GDM or vehicle offspring.

\section{Effects of Experimental GDM on \\ Mechanical Sensitivity in Offspring}

To determine the effect of GDM on mechanical sensitivity in adult offspring, baseline tactile thresholds were measured using the up-down method. Both female and male (Figure $3 \mathrm{~A}$ and $\mathrm{B}$ ) offspring from dams treated with STZ had significantly reduced withdrawal thresholds in both hind paws [left: $F_{(1,36)}=525.3$; right: $F_{(1,36)}=513.3$ ] compared to those of offspring from dams treated with VEH. This mechanical hypersensitivity was maintained at 12,13 and 14 weeks of offspring age, indicating that this pro-nociceptive phenotype is chronic.

We also investigated the potential sexual dimorphism of mechanical hypersensitivity in our model. We found that mechanical thresholds of female and male offspring from GDM dams were not different. Similar findings were observed in female and male offspring from VEH dams. These results indicate that this pro-nociceptive phenotype evoked by mechanical stimulation occurs in GDM offspring regardless of sex.
A

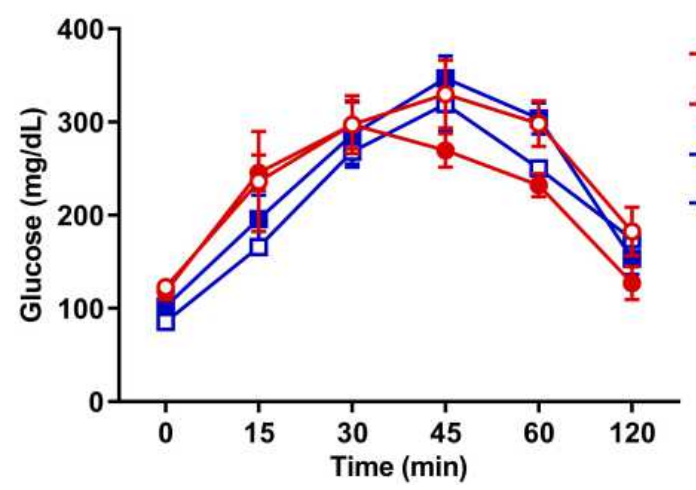

B

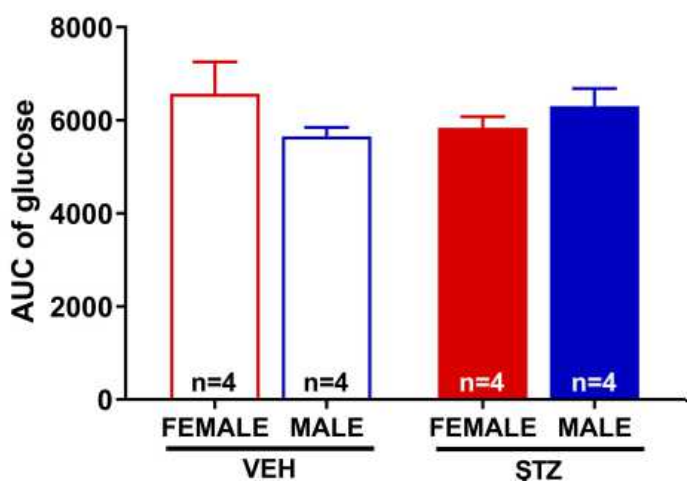

Figure 2 Oral glucose tolerance test in offspring. The administration of STZ during pregnancy did not modify glucose levels in female or male mice versus those mice born from dams treated with VEH (A). AUC of glucose levels did not show any significant differences $(\mathbf{B})$. Data are presented as mean \pm SEM; $n=4$ each.

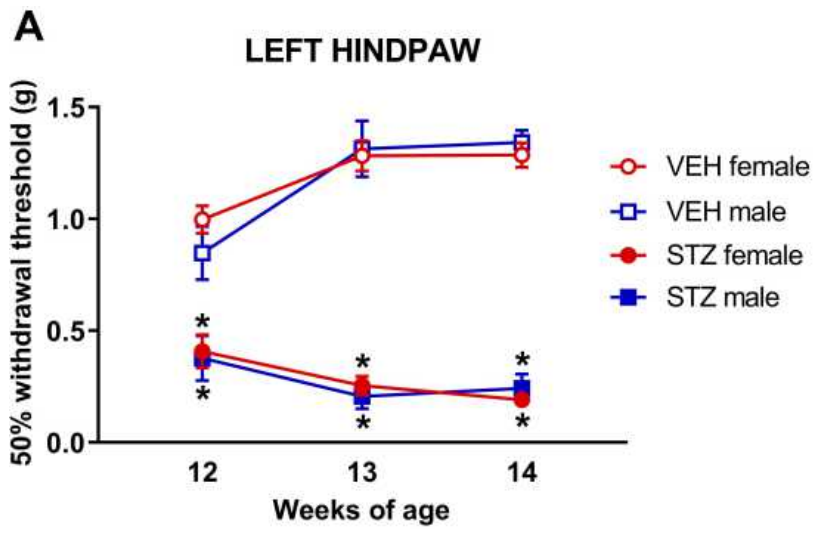

B

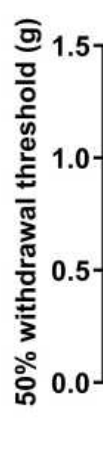

RIGHT HINDPAW

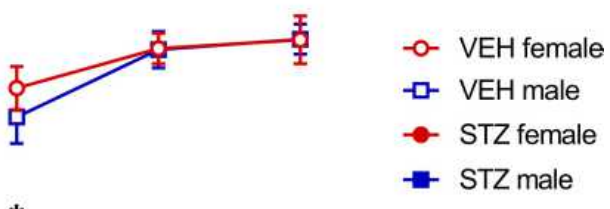

Figure 3 Experimental gestational diabetes mellitus significantly increases mechanical sensitivity in offspring. The administration of STZ during pregnancy significantly decreases the $50 \%$ withdrawal threshold in female and male (A and B) offspring vs VEH groups. Behavioral evaluation was performed in offspring at I2, I 3 and I4 weeks of age. Data are presented as mean \pm SEM; $n=10$ each. ${ }^{*} p<0.05$ vs respective control. Three-way repeated measures ANOVA followed by Tukey post-hoc test. 


\section{Effects of Experimental GDM on Capsaicin- Induced Pain-Like Behaviors in Offspring}

After at least 5 days since the last mechanical evaluation was completed, capsaicin test was performed in female and male offspring at 15 weeks of age (Figure 4). Injection of capsaicin into the hind paw plantar surface of mice produced immediate nociceptive responses of the injected paw. Results shown that female and male offspring from dams treated with STZ during pregnancy have a significantly greater number of flinches $\left[F_{(1,36)}=96.12\right.$, Figure $4 A$; and $F_{(1,36)}=96.35$, Figure $\left.4 B\right]$ and time spent guarding $\left[\mathrm{F}_{(1,36)}=40.24\right.$, Figure $4 \mathrm{C}$; and $\mathrm{F}_{(1,36)}$ $=40.24$, Figure 4D] than offspring from dams treated with $\mathrm{VEH}$.

We also investigated the potential sexual dimorphism of hypersensitivity induced by i.pl. capsaicin in our model. We found that flinching behaviors were greater in magnitude in male than female offspring from GDM dams only at the 5 min time point $\left[\mathrm{F}_{(1,36)}=2.022\right]$, but this difference disappeared in all other time points (Figure 4A). When we analyzed the AUC in male and female offspring from GDM dams, we did not find any difference (Figure 4B). We did not find any sexual dimorphism in guarding behavior in offspring from GDM dams at any time point studied (Figure 4C) and this was also the case when we analyzed these data as AUC (Figure 4D). No differences were observed between female and male offspring from VEH dams. These results indicate that this pro-nociceptive phenotype partially occurs in GDM more prominently in male than female offspring.

\section{A}

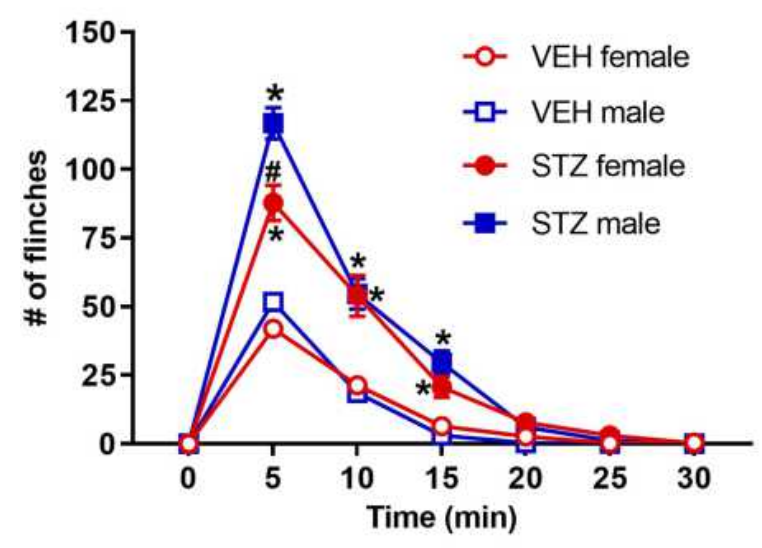

C

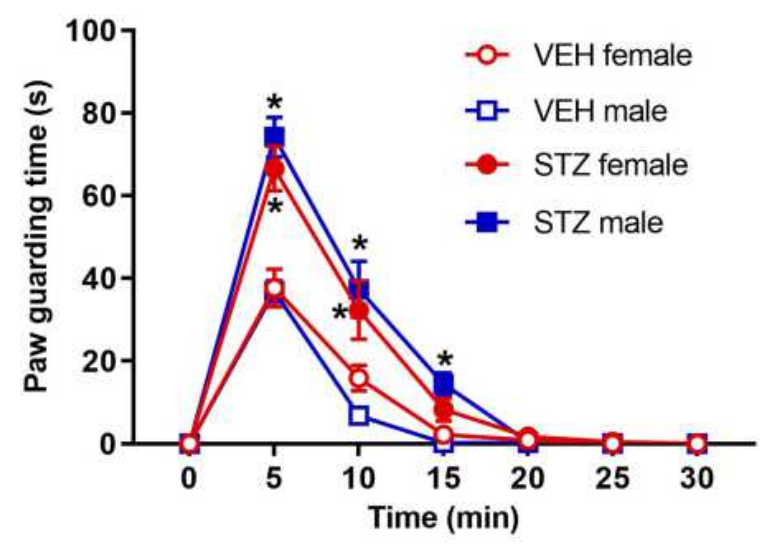

B

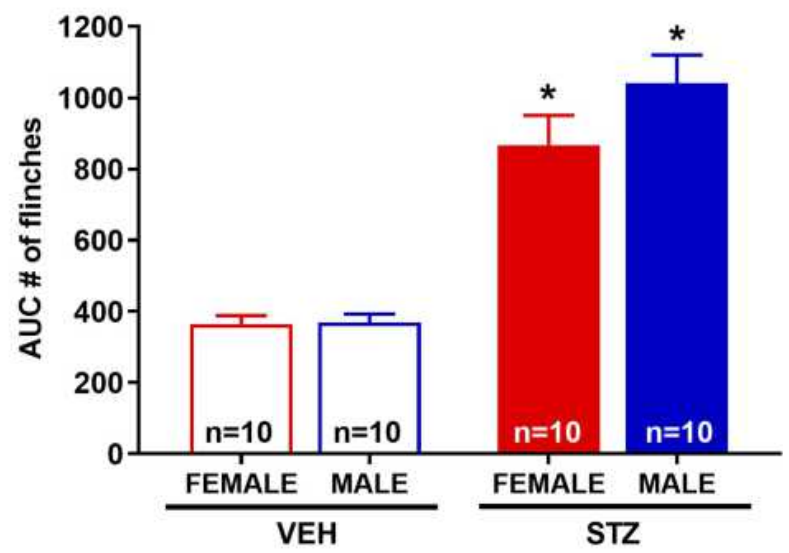

D

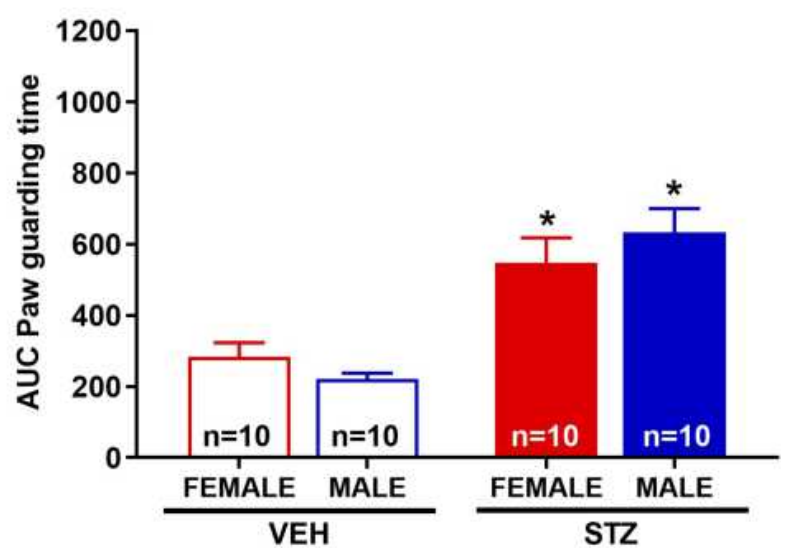

Figure 4 Experimental gestational diabetes mellitus significantly increases capsaicin-induced pain-like behaviors in offspring. Offspring from mice treated with STZ during pregnancy showed a greater number of flinches $(\mathbf{A})$ and time spent guarding (C) compared to offspring from mice treated with VEH. AUC were determinated in both, flinches (B) and guarding (D) behavior, we observe statistic differences between STZ group vs their respective control group (VEH) on female and male mice. Capsaicin test was performed when offspring were 15 weeks of age. Data are presented as mean \pm SEM; $n=10$ each. * ${ }^{*}<0.05$ vs respective control, ${ }^{\#}<0.05$ STZ female vs STZ male. Three-way repeated measures ANOVA (temporal course; (A, C)) or two-way ANOVA (AUC; (B, D)) followed by Tukey post-hoc test. 


\section{Effects of Experimental GDM in Offspring} Density of Epidermal PGP9. $5^{+}$and CGRP ${ }^{+}$ Nerve Fibers in the Glabrous Hind Paw Skin

In order to determine the density of epidermal PGP-9.5 and CGRP nerve fibers in the skin of offspring from dams treated with STZ or vehicle, we used IHC and confocal microscopy.
Figures 5 and 6 show representative confocal images of PGP9.5 (Figure 5A-D) and CGRP (Figure 6A-D) in the hind paw glabrous skin of 16-week-old offspring from VEH-treated and STZ-treated dams. Confocal images of the offspring hind paw skin showed that in the epidermis PGP-9.5 $5^{+}$fibers overlapped with each other, penetrate into the epidermis in a profuse way

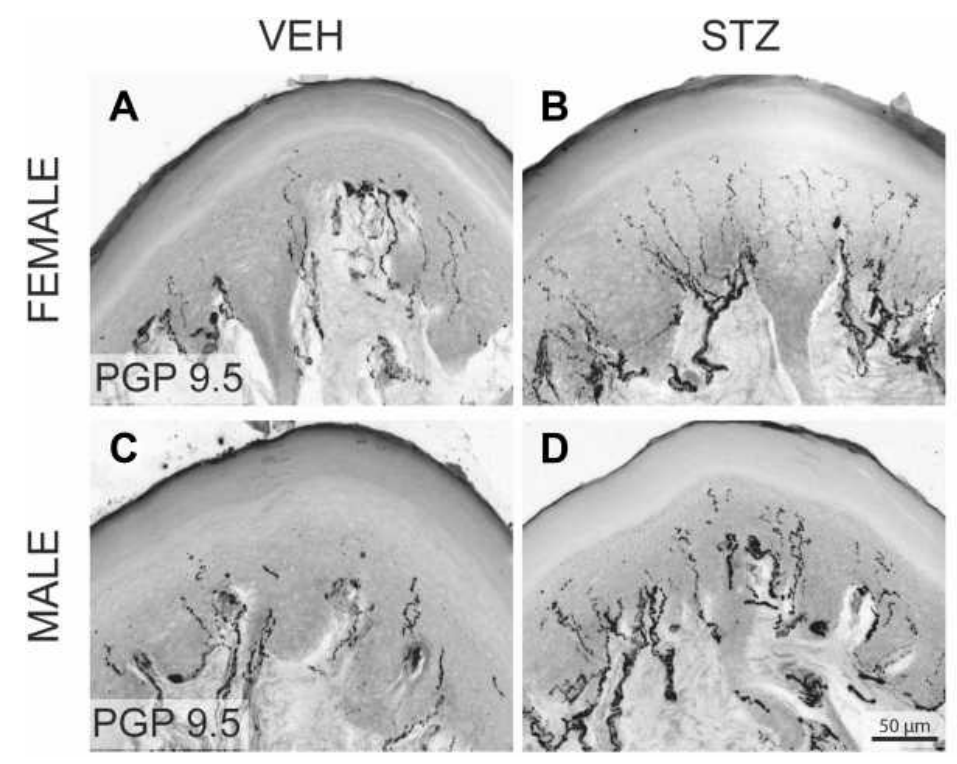

\section{$\mathbf{E}$}

PGP 9.5

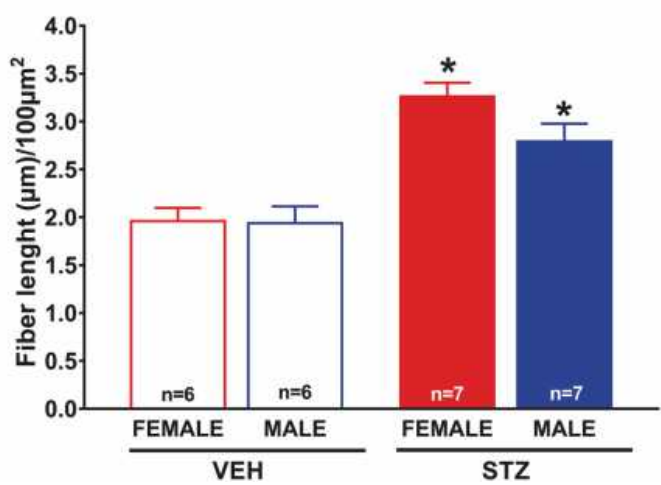

Figure 5 Offspring from diabetic dams have an increased density of intraepidermal PGP9.5 ${ }^{+}$nerve fibers in the glabrous hind paw skin. Representative confocal images of protein gene product-9.5 (PGP-9.5; (A-B)) in hind paw skin sections (20 $\mu \mathrm{m}$ thick) from female and male VEH ((A and C); respectively) and STZ offspring ((B and D); respectively) mice (bar is $50 \mu \mathrm{m})$. A significantly increased density of PGP-9.5 ${ }^{+}(\mathbf{E} ; \mathrm{n}=7)$ is observed in the hind paw skin of female and male $\mathrm{STZ}$ offspring vs VEH group ( $\mathrm{n}=6$ each). Data are presented as mean \pm SEM of length fibers; ${ }^{*} \mathrm{p}<0.05$ vs respective control. Two-way ANOVA followed by Tukey post-hoc test.
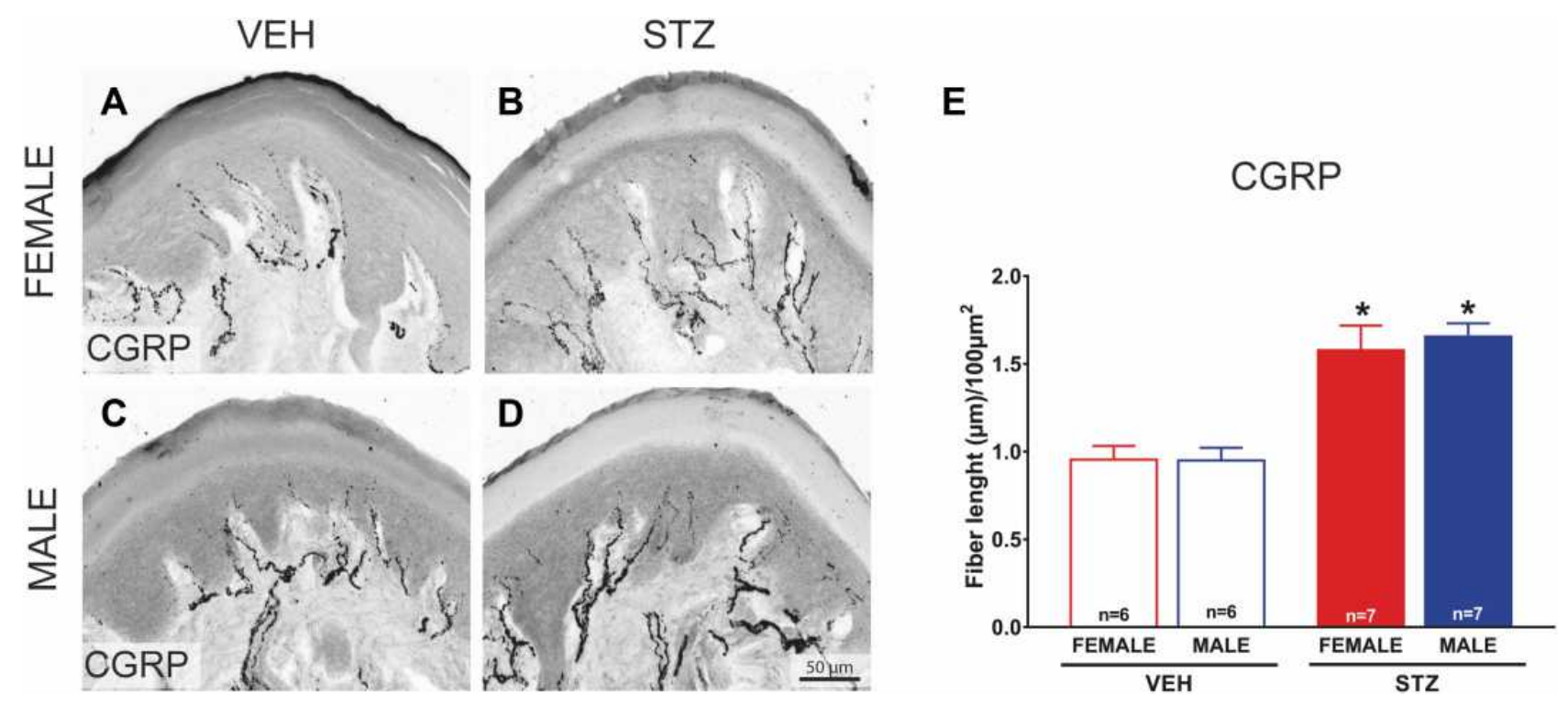

Figure 6 Offspring from diabetic dams have an increased density of intraepidermal CGRP ${ }^{+}$nerve fibers in glabrous hind paw skin. Representative confocal images of calcitonin gene-related peptide (CGRP; (A-B)) in hind paw skin sections (20 $\mu$ m thick) from female and male VEH ((A and C); respectively) and STZ offspring ((B and $\mathbf{D})$; respectively) mice (bar is $50 \mu \mathrm{m})$. A significantly increased density of $\mathrm{CGRP}^{+}(\mathrm{E} ; \mathrm{n}=7)$ is observed in the hind paw skin of female and male STZ offspring vs VEH group ( $\mathrm{n}=6$ each). Data are presented as mean \pm SEM of calcitonin gene-related peptide (CGRP length fibers; ${ }^{*}<0.05$ vs respective control. Two-way ANOVA followed by Tukey posthoc test. 
and formed thick fiber bundles (Figure 5A-D). $\mathrm{CGRP}^{+}$fibers displayed similar morphological distribution, some fibers penetrate into the epidermis where they became thinner, single, with obvious varicosities ${ }^{26}$ (Figure 6A-D). In female offspring, quantitative analysis revealed a significantly increased density of PGP-9.5 $5^{+}\left[\mathrm{F}_{(1,22)}=41.99\right.$, Figure 5E $]$ and $\mathrm{CGRP}^{+}$ $\left[F_{(1,22)}=20.61\right.$, Figure $\left.6 \mathrm{E}\right]$ in the hind paw skin of STZ offspring versus VEH group. Likewise, male offspring from STZ dams showed a significantly increased density of PGP-9.5 $\left[\mathrm{F}_{(1,22)}=41.99\right.$, Figure 5E $]$ and $\mathrm{CGRP}^{+}\left[\mathrm{F}_{(1,22)}=20.61\right.$, Figure $6 \mathrm{E}]$ in the hind paw skin compared to offspring from $\mathrm{VEH}$ dams. When we evaluated the potential sexual dimorphism in PGP-9. $5^{+}$and $\mathrm{CGRP}^{+}$staining, we did not find any difference between male and female offspring from either STZ or VEH treated dams.

\section{Discussion}

Our study produced two major findings: 1) That offspring from uncontrolled GDM dams develop features consistent with a particular diabetic peripheral neuropathy characterized by mechanical hypersensitivity, an amplified response to a nociceptive challenge (ie, capsaicin), an augmented ENFD, and an enhanced nociceptive molecular phenotype (ie, CGRP) in the skin. And 2) These neuropathic features in GDM offspring occur regardless of sex, however some parameters seem to display a sexual dimorphism.

Our results can be interpreted as consequences of an effective induction of a hyperglycemic state or GDM since our GDM model was successfully reproduced. For example, after the administration of STZ in dams, we registered a $33.33 \%$ of birth success, which is consistent with previous studies. ${ }^{14,27-29}$ Furthermore, in our hands, STZ-injected dams' blood glucose levels were 2.82 and 3.60 times higher on GD11 and prepartum day, respectively, than those from vehicletreated dams, in line with previous findings. ${ }^{10,30,31}$ Similarly, the GDM offspring body weight reduction observed in our experiments is in agreement with the available literature. $^{27-29,32,33}$ Additionally, our results showing that blood glucose levels of adult GDM offspring were within normal range are consistent with others' observations. ${ }^{33}$

In humans GDM develops due to changes in glucose metabolism during pregnancy. ${ }^{1,34}$ It has been widely reported that intrauterine exposure of maternal hyperglycemia negatively influences development during fetal and postnatal life, producing long-term cardiovascular or metabolic conditions. ${ }^{14,35-38}$
However, very little is known about the effects of GDM on nociceptive transmission in the progeny. The rationale to study potential consequences of GDM in the sensory system is based on the neurotoxic effects of hyperglycemic states in patients with diabetes, namely diabetic peripheral neuropathy. ${ }^{39}$

In rodents, GDM has been mimicked using surgical, genetic, or chemical approaches. ${ }^{40}$ To our knowledge, only two studies have used chemically induced GDM models to assess the potential effects of hyperglycemia during pregnancy in the offspring nociceptive system. The alloxan-induced GDM has been used to study potential effects of GDM in the peripheral nociceptive system in rat offspring. ${ }^{11}$ This model produces an insulin-dependent state of diabetes via pancreatic beta-cell toxicity. That study shows that GDM adult offspring are more sensitive to thermal stimulation under normal conditions and display an exacerbated response to thermal stimulation following an inflammatory challenge via carrageenan, in association with an increased proportion in pro-nociceptive dorsal root ganglia sensory neurons. ${ }^{11}$ Another study that used a different chemically induced GDM with a similar mechanism to alloxan, ie, beta cell toxicity using STZ, evaluated changes in the central nervous system in mice. ${ }^{41}$ However, until now whether this murine STZ GDM model resulted in peripheral nociceptive system alterations was unknown. Our current studies using the STZ GDM model recapitulate the pro-nociceptive behaviors in association with an increase in peripheral nociceptive neurons observed in alloxan-GDM offspring, which further demonstrate that hyperglycemic states during pregnancy result in a GDM peripheral neuropathy characterized by a pro-nociceptive behavioral, anatomical, and molecular phenotype in rodent offspring.

Our and others' findings demonstrating that the GDM results in a pro-nociceptive behavioral phenotype in rodent offspring is consistent with the behavioral presentation of diabetic peripheral neuropathy that develops in adult rodents $^{42}$ and humans ${ }^{43}$ with diabetes mellitus. Classic diabetic peripheral neuropathy in rodents ${ }^{44-48}$ and humans ${ }^{43}$ is also characterized by a "dying back" of long peripheral sensory fibers with a lesser damage to cell bodies at the DRG level, that results in the "stocking and glove" sensorial pattern of tingling, numbness, and pain. ${ }^{43}$ For this reason, studies evaluating the effects of hyperglycemia in DRG neurons might provide misleading information since neuronal cell bodies are relatively preserved in diabetic peripheral neuropathy. Thus, the observation that GDM offspring display an increase in DRG nociceptive neurons (substance $\mathrm{P}$ peptidergic and non-peptidergic neurons) and a decrease in DRG myelinated neurons (presumably non-nociceptive fibers) ${ }^{11}$ needed further confirmation by 
evaluating skin innervation, which has not been done in GDM offspring. Our anatomical studies in skin demonstrate an increase in general ENFD and CGRP positive ENFD density, which confirms the contrast pathological phenotype between classic diabetic peripheral neuropathy (reduction in ENFD) and GDM offspring peripheral neuropathy. Interestingly, the increase in this subset of peptidergic epidermal nerve fibers in GDM offspring is associated with their enhanced behavioral responses to capsaicin, which binds to TRPV1 receptors that typically are expressed in CGRP positive sensory neurons. ${ }^{49}$ Thus, our study demonstrates that an uncontrolled hyperglycemic state during pregnancy is sufficient to induce a distinct peripheral neuropathy in offspring that is characterized by a behavioral, anatomical, and molecular pro-nociceptive signature. Furthermore, our data indicate that GDM peripheral neuropathy in offspring is chronic since our pathological and behavioral findings are strikingly present $12-14$ weeks after birth. Notably, these pro-nociceptive neuropathy does not seem to be reversible after glycemic correction because GDM offspring displayed normal blood glucose levels after birth. This finding could have major clinical implications if they are translated to humans since finding a curative treatment could be challenging and thus, preventive measures should be investigated. Yet, whether GDM offspring neuropathy could be prevented by glycemic control in the GDM dams during pregnancy remains to be elucidated. Certainly, our study sets the grounds to test this hypothesis.

Numerous studies have shown sexual dimorphism of painlike behaviors in pre-clinical models of diabetic peripheral neuropathy in diabetes mellitus type 1 and type $2 .{ }^{50,51}$ Since this sex-related differences had not been investigated in GDM offspring neuropathy, our second aim was focused on the hypothesis that sexual dimorphism would be present in the outcomes evaluated in GDM offspring. Interestingly, we found that the overt pro-nociceptive GDM neuropathy in offspring occurred regardless of the sex of offspring. However, the intensity of behavioral responses to the capsaicin challenge was greater in male GDM offspring than in their female counterparts. This more intense pain behavior was observed only at one time point studied, and the overall responses to capsaicin when evaluated using AUC analysis show no differences between male and female GDM offspring. It is likely that this finding is not biologically significant since guarding behavior following capsaicin, and mechanically evoked pain-like behaviors did not display sexual dimorphism. Thus, this apparent statistical sexual difference should be interpreted with caution.
We recognize that there are alternative explanations to our findings. For example, the increased pain sensitivity as well as the increased density of PGP 9.5 and CGRP nerve axons in the epidermis could be due to direct toxic effects induced by STZ in the developing embryos, since this was injected i.p. at the seventh day of gestation. However, if this was the case, one would anticipate skin innervation to be reduced, and in fact our data show the opposite. More importantly our OGTT in offspring demonstrate a normal pancreatic function in response to oral glucose, which rules out a potential toxic effect of STZ on embryos and the possibility of inappropriate glucose metabolism in fetuses. Accordingly, in rhesus monkeys it has been shown that even STZ crosses the placenta it does not reach the pancreas of the fetuses. ${ }^{52}$ Notably, in a STZ model of GDM in mice in which fetuses were implanted in diabetic dams through in vitro fertilization three weeks after STZ treatment, offspring displayed the same growth restriction observed in our studies, and this occurs regardless of hyperglycemia status of oocyte donors (pain and ENFD were not evaluated) ${ }^{53}$ These data together further support the notion that the offspring phenotype observed in our studies is not due to a direct action of STZ on embryos but rather to the GDM hyperglycemia in dams. We do recognize that the GDM's effects in offspring in rodent models are complex and other factors could play a role. For example, dams with STZ-induced gestational diabetes results in differential changes in placental growth factors and nutrients transporters that depend upon the number of pups per pregnancy, the different changes in the size of the placenta, the degree of dams' hyperglycemia, etc. ${ }^{54}$

We also recognize that the mechanisms behind the increased pain sensitivity and nerve fiber density are unknown. Future studies are needed to determine levels of NGF and other neurotrophins (eg, BDNF) in the offspring born of diabetic dams since these neurotrophins are essential for the survival of nociceptive neurons innervating skin. In any case, our study provides an updated perspective of the long-term effects of GDM on acute nociceptive transmission and density of nerve fibers in adult offspring. The differential presentation of this condition when compared to adult diabetic peripheral neuropathy suggests that non-controlled hyperglycemia alters the biology of the nociceptive system through developmental mechanisms that do not exist in adulthood. Also, as mentioned above, whether this could be prevented or treated once it is established are also intriguing hypotheses that we are currently investigating in our laboratory. The consequences for the progeny of uncontrolled GDM dams could be devastating since inflammatory conditions could result in exacerbated pain states that could lead to chronic pain. Whether pain syndromes are 
more prevalent, or pain is more intense in the progeny of uncontrolled or controlled GDM dams is another testable hypothesis with significant clinical and public health implications.

\section{Conclusion}

In summary, the present study shows that GDM induced by the administration of STZ exacerbated the capsaicin-induced acute pain-like behaviors as well as increased the density of PGP 9.5 and CGRP epidermal nerve axons in both female and male offspring, suggesting that GDM may result in a dysfunction in nociceptive processing. This pro-nociceptive phenotype seems pathophysiologically different to adult peripheral diabetic neuropathy, it is long lasting, and does not seem reversible upon normalization of blood glucose. The implications of peripheral GDM offspring neuropathy could be clinically devastating. Our study sets the foundation to further investigate this phenomenon in our patient population.

\section{Acknowledgments}

This research was supported by the National Council of Science and Technology Foundation of Mexico (CONACyT) project CB 2017-2018/A1-S-27869 (EM-I); Universidad Autónoma de Tamaulipas PFI2018-CS-03 (EM-I); NINDS grant R01NS114653 (EAR-S); NCI grant R21CA248106 (EAR-S); Wake Forest University School of Medicine Department of Anesthesiology Research Funds (EAR-S); Wake Forest Baptist Comprehensive Cancer Center - Cancer Career Development Award to Promote Diversity (EAR-S); National Center for Advancing Translational Sciences (NCATS), NIH, grant (UL1TR001420 - Ignition Fund Pilot Award (EAR-S). The content is solely the responsibility of the authors and does not necessarily represent the official views of the NIH.

\section{Disclosure}

The authors report no conflicts of interest in this work.

\section{References}

1. Wendland EM, Torloni MR, Falavigna M, et al. Gestational diabetes and pregnancy outcomes-a systematic review of the World Health Organization (WHO) and the International Association of Diabetes in Pregnancy Study Groups (IADPSG) diagnostic criteria. BMC Pregnancy Childbirth. 2012;12:23.

2. Group HSCR, Metzger BE, Lowe LP, et al. Hyperglycemia and adverse pregnancy outcomes. $N$ Engl J Med. 2008;358(19):19 91-2002.
3. McIntyre HD, Catalano P, Zhang C, Desoye G, Mathiesen ER, Damm P. Gestational diabetes mellitus. Nat Rev Dis Primers. 2019;5(1):47. doi:10.1038/s41572-019-0098-8

4. Najafi L, Abedini A, Kadivar M, et al. Gestational diabetes mellitus: the correlation between umbilical coiling index, and intrapartum as well as neonatal outcomes. J Diabetes Metab Disord. 2019;18 (1):51-57. doi:10.1007/s40200-019-00389-z

5. Duong V, Davis B, Falhammar H. Pregnancy and neonatal outcomes in Indigenous Australians with diabetes in pregnancy. World $J$ Diabetes. 2015;6(6):880-888. doi:10.4239/wjd.v6.i6.880

6. Friedman JE. Developmental programming of obesity and diabetes in mouse, monkey, and man in 2018: where are we headed? Diabetes. 2018;67(11):2137-2151.

7. Moon JH, Kwak SH, Jang HC. Prevention of type 2 diabetes mellitus in women with previous gestational diabetes mellitus. Korean J Intern Med. 2017;32(1):26-41.

8. Kramer CK, Campbell S, Retnakaran R. Gestational diabetes and the risk of cardiovascular disease in women: a systematic review and meta-analysis. Diabetologia. 2019;62(6):905-914.

9. Shostrom DCV, Sun Y, Oleson JJ, Snetselaar LG, Bao W. History of gestational diabetes mellitus in relation to cardiovascular disease and cardiovascular risk factors in US Women. Front Endocrinol. 2017;8:144.

10. Nguyen HT, Bhattarai JP, Park SJ, Lee JC, Cho DH, Han SK. Enhanced GABA action on the substantia gelatinosa neurons of the medullary dorsal horn in the offspring of streptozotocin-injected mice. J Diabetes Complications. 2015;29(5):629-636. doi:10.1016/ j.jdiacomp.2015.03.007

11. Campos Lima T, Lemes JBP, Capop T, de Lima LB. Altered morphology and function of the peripheral nociceptive system in the offspring of diabetic rats. Int J Dev Neurosci. 2020;80(4):267-275. doi:10.1002/jdn.10023

12. Aaberg ML, Burch DM, Hud ZR, Zacharias MP. Gender differences in the onset of diabetic neuropathy. J Diabetes Complications. 2008;22(2):83-87. doi:10.1016/j.jdiacomp.2007.06.009

13. Zimmermann M. Ethical guidelines for investigations of experimental pain in conscious animals. Pain. 1983;16(2):109-110. doi:10.10 16/0304-3959(83)90201-4

14. Hokke SN, Armitage JA, Puelles VG, et al. Altered ureteric branching morphogenesis and nephron endowment in offspring of diabetic and insulin-treated pregnancy. PLoS One. 2013;8(3):e58243. doi:10.1371/journal.pone.0058243

15. Nagy C, Einwallner E. Study of In Vivo Glucose Metabolism in High-fat Diet-fed Mice Using Oral Glucose Tolerance Test (OGTT) and Insulin Tolerance Test (ITT. $J$ Vis Exp. 2018;131. doi:10.3791/56672

16. Chaplan SR, Bach FW, Pogrel JW, Chung JM, Yaksh TL. Quantitative assessment of tactile allodynia in the rat paw. $J$ Neurosci Methods. 1994;53(1):55-63. doi:10.1016/0165-0270(94)90144-9

17. Dixon WJ. Efficient analysis of experimental observations. Annu Rev Pharmacol Toxicol. 1980;20:441-462. doi:10.1146/annurev.pa.20.04 0180.002301

18. Sakurada T, Katsumata K, Tan-No K, Sakurada S, Kisara K. The capsaicin test in mice for evaluating tachykinin antagonists in the spinal cord. Neuropharmacology. 1992;31(12):1279-1285. doi:10.10 16/0028-3908(92)90057-V

19. Sakurada T, Mizoguchi H, Kuwahata H, et al. Intraplantar injection of bergamot essential oil induces peripheral antinociception mediated by opioid mechanism. Pharmacol Biochem Behav. 2011;97 (3):436-443. doi:10.1016/j.pbb.2010.09.020

20. Pham VM, Tu NH, Katano $\mathrm{T}$, et al. Impaired peripheral nerve regeneration in type-2 diabetic mouse model. Eur $J$ Neurosci. 2018;47(2):126-139. doi:10.1111/ejn.13771

21. Piazza FV, Segabinazi E, de Meireles ALF, et al. Severe uncontrolled maternal hyperglycemia induces microsomia and neurodevelopment delay accompanied by apoptosis, cellular survival, and neuroinflammatory deregulation in rat offspring hippocampus. Cell $\mathrm{Mol}$ Neurobiol. 2019;39(3):401-414. doi:10.1007/s10571-019-00658-8 
22. Kruse MS, Barutta J, Vega MC, Coirini H. Down regulation of the proliferation and apoptotic pathways in the embryonic brain of diabetic rats. Cell Mol Neurobiol. 2012;32(6):1031-1037. doi:10.1007/ s10571-012-9820-8

23. Dritsakou K, Liosis G, Valsami G, Polychronopoulos E, Skouroliakou M. The impact of maternal- and neonatal-associated factors on human milk's macronutrients and energy. J Matern Fetal Neonatal Med. 2017;30(11):1302-1308. doi:10.1080/14767058.20 16.1212329

24. Plagemann A, Harder T, Melchior K, Rake A, Rohde W, Dorner G. Elevation of hypothalamic neuropeptide Y-neurons in adult offspring of diabetic mother rats. Neuroreport. 1999;10(15):3211-3216. doi:10.1097/00001756-199910190-00016

25. Pereira TJ, Fonseca MA, Campbell KE, et al. Maternal obesity characterized by gestational diabetes increases the susceptibility of rat offspring to hepatic steatosis via a disrupted liver metabolome. J Physiol. 2015;593(14):3181-3197. doi:10.1113/JP270429

26. Ma W, Bisby MA. Calcitonin gene-related peptide, substance P and protein gene product 9.5 immunoreactive axonal fibers in the rat footpad skin following partial sciatic nerve injuries. J Neurocytol. 2000;29(4):249-262. doi:10.1023/A:1026519720352

27. Wang Y, Feng Q, Niu X, et al. The preventive effect of zuogui wan on offspring rats' impaired glucose tolerance whose mothers had gestational diabetes mellitus. Evid Based Complement Alternat Med. 2016;2016:9417362.

28. Zeng CJ, Zhang L, Yang HX. Effects of severe hyperglycaemia in pregnancy and early overfeeding on islet development and insulin resistance. Zhonghua Fu Chan Ke Za Zhi. 2010;45(9):658-663.

29. Blondeau B, Joly B, Perret C, et al. Exposure in utero to maternal diabetes leads to glucose intolerance and high blood pressure with no major effects on lipid metabolism. Diabetes Metab. 2011;37 (3):245-251. doi:10.1016/j.diabet.2010.10.008

30. Goss JR, Goins WF, Lacomis D, Mata M, Glorioso JC, Fink DJ. Herpes simplex-mediated gene transfer of nerve growth factor protects against peripheral neuropathy in streptozotocin-induced diabetes in the mouse. Diabetes. 2002;51(7):2227-2232. doi:10.2337/diabetes.51.7.2227

31. Martin PM, Roon P, Van Ells TK, Ganapathy V, Smith SB. Death of retinal neurons in streptozotocin-induced diabetic mice. Invest Ophthalmol Vis Sci. 2004;45(9):3330-3336. doi:10.1167/iovs.04-0247

32. Mdaki KS, Larsen TD, Wachal AL, et al. Maternal high-fat diet impairs cardiac function in offspring of diabetic pregnancy through metabolic stress and mitochondrial dysfunction. Am J Physiol Heart Circ Physiol. 2016;310(6):H681-692. doi:10.1152/ajpheart.00795.2015

33. Inoguchi $\mathrm{Y}$, Ichiyanagi $\mathrm{K}$, Ohishi $\mathrm{H}$, et al. Poorly controlled diabetes during pregnancy and lactation activates the Foxo1 pathway and causes glucose intolerance in adult offspring. Sci Rep. 2019;9 (1):10181. doi:10.1038/s41598-019-46638-2

34. American Diabetes A. Improving Care and Promoting Health in Populations: standards of Medical Care in Diabetes-2020. Diabetes Care. 2020;43(Suppl 1):S7-S13. doi:10.2337/dc20-S001

35. Wren C, Birrell G, Hawthorne G. Cardiovascular malformations in infants of diabetic mothers. Heart. 2003;89(10):1217-1220. doi:10. 1136/heart.89.10.1217

36. Dheen ST, Tay SS, Boran J, et al. Recent studies on neural tube defects in embryos of diabetic pregnancy: an overview. Curr Med Chem. 2009;16(18):2345-2354. doi:10.2174/092986709788453069

37. Clausen TD, Mathiesen ER, Hansen T, et al. High prevalence of type 2 diabetes and pre-diabetes in adult offspring of women with gestational diabetes mellitus or type 1 diabetes: the role of intrauterine hyperglycemia. Diabetes Care. 2008;31(2):340-346. doi:10.2337/dc07-1596

38. Catalano PM, McIntyre HD, Cruickshank JK, et al. The hyperglycemia and adverse pregnancy outcome study: associations of GDM and obesity with pregnancy outcomes. Diabetes Care. 2012;35(4):7 80-786. doi:10.2337/dc11-1790
39. Selvarajah D, Kar D, Khunti K, et al. Diabetic peripheral neuropathy: advances in diagnosis and strategies for screening and early intervention. Lancet Diabetes Endocrinol. 2019;7(12):938-948. doi:10.1016/S2213-8587(19)30081-6

40. Jawerbaum A, White V. Animal models in diabetes and pregnancy. Endocr Rev. 2010;31(5):680-701. doi:10.1210/er.2009-0038

41. Liao DM, Ng YK, Tay SSW, Ling EA, Dheen ST. Altered gene expression with abnormal patterning of the telencephalon in embryos of diabetic Albino Swiss mice. Diabetologia. 2004;47(3):523-531. doi:10.1007/s00125-004-1351-5

42. Jolivalt CG, Frizzi KE, Guernsey L, et al. Peripheral Neuropathy in Mouse Models of Diabetes. Curr Protoc Mouse Biol. 2016;6 (3):223-255. doi:10.1002/cpmo.11

43. Feldman EL, Callaghan BC, Pop-Busui R, et al. Diabetic neuropathy. Nat Rev Dis Primers. 2019;5(1):41. doi:10.1038/s41572-019-0092-1

44. Properzi G, Francavilla S, Poccia G, et al. Early increase precedes a depletion of VIP and PGP-9.5 in the skin of insulin-dependent diabetics-correlation between quantitative immunohistochemistry and clinical assessment of peripheral neuropathy. $J$ Pathol. 1993;169(2):269-277. doi:10.1002/path.1711690215

45. Levy DM, Terenghi G, Gu XH, Abraham RR, Springall DR, Polak JM. Immunohistochemical measurements of nerves and neuropeptides in diabetic skin: relationship to tests of neurological function. Diabetologia. 1992;35(9):889-897. doi:10.1007/BF0039 9938

46. Lindberger M, Schroder HD, Schultzberg M, et al. Nerve fibre studies in skin biopsies in peripheral neuropathies. I. Immunohistochemical analysis of neuropeptides in diabetes mellitus. J Neurol Sci. 1989;93(2-3):289-296. doi:10.1016/0022510X(89)90198-6

47. Beiswenger KK, Calcutt NA, Mizisin AP. Epidermal nerve fiber quantification in the assessment of diabetic neuropathy. Acta Histochem. 2008;110(5):351-362. doi:10.1016/j.acthis.2007.12.004

48. Lopez-Soldado I, Herrera E. Different diabetogenic response to moderate doses of streptozotocin in pregnant rats, and its long-term consequences in the offspring. Exp Diabesity Res. 2003;4 (2):107-118. doi:10.1155/EDR.2003.107

49. Sharrad DF, Hibberd TJ, Kyloh MA, Brookes SJ, Spencer NJ. Quantitative immunohistochemical co-localization of TRPV1 and CGRP in varicose axons of the murine oesophagus, stomach and colorectum. Neurosci Lett. 2015;599:164-171. doi:10.1016/j. neulet.2015.05.020

50. Ferhatovic L, Banozic A, Kostic S, Sapunar D, Puljak L. Sex differences in pain-related behavior and expression of calcium/calmodulin-dependent protein kinase II in dorsal root ganglia of rats with diabetes type 1 and type 2. Acta Histochem. 2013;115(5):496-504. doi:10.1016/j.acthis.2012.11.006

51. O'Brien PD, Hur J, Robell NJ, Hayes JM, Sakowski SA, Feldman EL. Gender-specific differences in diabetic neuropathy in BTBR ob/ob mice. J Diabetes Complications. 2016;30(1):30-37. doi:10.1016/j.jdiacomp.2015.09.018

52. Reynolds WA, Chez RA, Bhuyan BK, Neil GL. Placental transfer of streptozotocin in the rhesus monkey. Diabetes. 1974;23(9):777-782. doi:10.2337/diab.23.9.777

53. Tsai PS, Yamauchi Y, Riel JM, Ward MA. Pregnancy environment, and not preconception, leads to fetal growth restriction and congenital abnormalities associated with diabetes. Sci Rep. 2020;10(1):12254. doi:10.1038/s41598-020-69247-w

54. Cisse O, Fajardy I, Dickes-Coopman A, et al. Mild gestational hyperglycemia in rat induces fetal overgrowth and modulates placental growth factors and nutrient transporters expression. PLoS One. 2013;8(5):e64251. 


\section{Publish your work in this journal}

The Journal of Pain Research is an international, peer reviewed, open access, online journal that welcomes laboratory and clinical findings in the fields of pain research and the prevention and management of pain. Original research, reviews, symposium reports, hypothesis formation and commentaries are all considered for publication. The manuscript management system is completely online and includes a very quick and fair peer-review system, which is all easy to use. Visit http:// www.dovepress.com/testimonials.php to read real quotes from published authors.

Submit your manuscript here: https://www.dovepress.com/journal-of-pain-research-journal 